\title{
Tetracapsuloides bryosalmonae (Myxozoa: Malacosporea) portal of entry into the fish host
}

\author{
D. S. Grabner, M. El-Matbouli* \\ Fish Medicine and Livestock Management, Department for Farm Animals and Veterinary Public Health, \\ University of Veterinary Medicine, Veterinärplatz 1, 1210 Vienna, Austria
}

\begin{abstract}
The portal of entry and the penetration process of the myxozoan parasite Tetracapsuloides bryosalmonae are still poorly understood. In the present study, spores of $T$. bryosalmonae derived from the bryozoan host (malacospores) were activated chemically and mechanically to investigate their reaction after attachment to the fish host in vitro. Amoeboid movement of both sporoplasms was shown for the first time. The morphology of malacospores was assessed using scanning electron microscopy (SEM). Openings of the polar capsules and released polar filaments were visible. One sporoplasm was observed leaving the spore shell. Laboratory exposure experiments of juvenile rainbow trout Oncorhynchus mykiss to spores of $T$. bryosalmonae were also conducted. Single fish were incubated with 1000 to 2000 spores in $100 \mathrm{ml}$ of water for 5 to $60 \mathrm{~min}$. Immunohistochemically stained sections of skin and gills were examined using light microscopy, as well as ultra thin sections using transmission electron microscopy (TEM), to investigate attachment and early penetration. Whole fish and excised gills of fish exposed to a spore suspension were fixed and prepared for scanning electron microscopy. Attached and penetrating stages were found only on or in the gills, and not in the skin. Due to the low overall number of spores, only a few spores were found adjacent to the gill epithelium in TEM. No parasite stages were found on the samples used for SEM. These results indicate that the gills are the preferred entry loci for the amoeboid sporoplasms of T. bryosalmonae into the fish host.
\end{abstract}

KEY WORDS: Myxozoa $\cdot$ Malacosporea $\cdot$ Penetration $\cdot$ PKD $\cdot$ Portal of entry $\cdot$ Infection - Resale or republication not permitted without written consent of the publisher

\section{INTRODUCTION}

Tetracapsuloides bryosalmonae causes proliferative kidney disease (PKD) in salmonid fish. This parasite can be found in Europe and North America and may cause high losses in trout aquaculture (Hedrick et al. 1993). Additionally, PKD is suspected to be responsible for the decline of wild brown trout Salmo trutta and salmon Salmo salar populations (Wahli et al. 2002, Sterud et al. 2007). The development of T. bryosalmonae in the kidney of the fish host has been described in detail by Ferguson \& Needham (1978), Kent \& Hedrick (1986), Clifton-Hadley et al. (1987) and Morris \& Adams (2008), whereas the route of entry of the sporoplasm into the fish is widely unknown. Therefore, studies addressing the invasion strategy of this parasite are required to help in understanding the biology of this unique group of Bryozoa-infecting myxozoans. During the process of infection, the free-floating actinospores of myxozoans are activated by chemical stimulants from the fish mucus and mechanically upon contact with fish surfaces like gills, skin or buccal cavity. Spores discharge polar filaments that attach to the host. Subsequently, the sporoplasm leaves the spore shell and penetrates the epithelium of the host (Kallert et al. 2005,2007 ). As the spores of $T$. bryosalmonae that are released from the bryozoan host (malacospores) have the same cellular organization as the actinospores of myxosporeans, a similar mode of infection can be postulated.

Results of previous studies on Tetracapsuloides bryosalmonae indicated that the gills (Morris et al. 2000) and epidermal mucus cells (Longshaw et al. 2002) seem to be the portals through which the para- 
site enters the fish host. However, visualization of developmental stages of $T$. bryosalmonae in the previous studies did not provide adequate information about the mode of penetration and the chronological progression of early development. As the abundance of Malacosporea-infected bryozoans is usually low (Anderson et al. 1999, Okamura et al. 2001, Okamura $\&$ Wood 2002), the attachment to the host and the penetration process of these few spores must be achieved by an efficient mechanism. It has already been shown that a single spore is sufficient to infect a fish and to cause clinical symptoms of PKD (McGurk et al. 2006). In the present study, we investigated whether the skin, gills or both organs are the main portals of entry for $T$. bryosalmonae into the fish and attempted to characterize the attachment and penetration process in detail. Stages during and shortly after penetration were visualized using light and electron microscopy. To show the reaction of $T$. bryosalmonae spores from bryozoans after contact with the host, in vitro activation experiments were conducted. Additionally, the malacospores were examined using scanning electron microscopy (SEM) for the first time.

\section{MATERIALS AND METHODS}

Fish and infected Bryozoa. For the experiments, specific pathogen free (SPF) rainbow trout Oncorhynchus mykiss fry (3 mo post hatch, $\sim 3 \mathrm{~cm}$ length) were used. The fish were kept in dechlorinated tap water at 10 to $12^{\circ} \mathrm{C}$ until the start of the experiments.

Colonies of Fredericella sultana that were laboratory infected with Tetracapsuloides bryosalmonae were kept in a laboratory culture system according to Morris et al. (2002) and Grabner \& El-Matbouli (2008) at a water temperature of $15^{\circ} \mathrm{C}$. To obtain adequate amounts of $T$. bryosalmonae spores, laboratory infected colonies with zooids containing mature spore sacs or free spores in the coelomic fluid were dissected. For this purpose, overtly infected parts of the bryozoan colonies and spore sacs were torn apart with forceps and needles on a microscope slide. The spores were washed with a small amount of tap water into a $5 \mathrm{ml}$ glass vial and stored at $4^{\circ} \mathrm{C}$ for $<2 \mathrm{~h}$ until use. By counting $20 \mu \mathrm{l}$ aliquots of the spore suspension, the approximate spore number was determined.

Activation of spores. Rainbow trout mucus was obtained and purified according to Kallert et al. (2005). Briefly, trout mucus was scraped off, homogenized, and centrifuged, and the supernatant was then used for activation. Spores were activated using the modified procedure of Kallert et al. (2005) by pipetting $14 \mu \mathrm{l}$ of spore suspension and $6 \mu \mathrm{l}$ of trout mucus homogenate up and down $3 \times$. Subsequently, a cover slip was carefully placed on the slide without applying any pressure and the spores were investigated with a phase contrast microscope (Zeiss).

Scanning electron microscopy (SEM). Malacospores, whole fish and gills incubated with 1000 to 2000 spores for 5 and 15 min were prepared for SEM as follows. Mature spores were obtained as described above, while care was taken to minimize the amount of water for washing the spores from the slide $(\sim 200 \mu \mathrm{l})$. For fixation, $2 \%$ glutaraldehyde in Soerensen's phosphate buffer ( $\mathrm{pH}$ 7.4) was added to the spore suspension. After a minimum of $24 \mathrm{~h}$ fixation, the sample was centrifuged (Cytospin 3, Shandon) at $1000 \mathrm{rpm}$ for $10 \mathrm{~min}$ to collect the spores on an L-lysin-coated slide. Whole fish and gills dissected from the fish after the respective incubation time were also fixed in $2 \%$ glutaraldehyde in phosphate buffer. Both spores on the slides and gill/fish samples were washed with phosphoric buffer for $2 \mathrm{~h}$, and dehydrated in a graded acetone series. The dehydrated sample was critical-point-dried, sputtered with platinum and examined with a digital scanning electron microscope (Zeiss DSM 950).

Light and transmission electron microscopy (TEM). For the histological examination of the penetration process on the surface and inside of the tissues, each rainbow trout was exposed to 1000 to 2000 spores in $100 \mathrm{ml}$ of water at $15^{\circ} \mathrm{C}$. This procedure was repeated with 2 fish at exposure times of 5, 10, 20, 30 and 60 min. Fish were killed with overdoses of the anaesthetic tricaine-methanesulfonate (MS 222, Sigma-Aldrich). Subsequently, gills, pieces of the skin and fins were removed and fixed immediately in buffered formalin for light microscopy and in $2.5 \%$ glutaraldehyde in Soerensen's phosphate buffer for TEM.

The formalin fixed samples were embedded in paraffin (Tissue-Tek VIP, Sakura Bayer Diagnostics). Sections were cut at $5 \mu \mathrm{m}$ (1140 Autocut, ReichertJung) and either stained with haematoxylin \& eosin (H\&E) or processed for immunohistochemistry (IHC). For IHC staining, the Tetracapsuloides bryosalmonaespecific monoclonal antibody P01 (Aquatic Diagnostics) was used according to the manufacturer's instructions. Sections were counterstained with haematoxylin. Kidney samples from an SPF carp and a PKDinfected rainbow trout were used as negative and positive controls respectively.

Samples for TEM were post-fixed in $1 \%$ osmium tetroxide in Soerensen's buffer for $2 \mathrm{~h}$, dehydrated in a graded acetone series, and embedded in epon resin. Semi and ultra thin sections were cut on a microtome (Reichert-Jung Ultracut). Semi thin sections were stained with toluidine blue. Ultra thin sections were contrasted with lead citrate and uranyl acetate and viewed using an electron microscope (Zeiss EM 10). 


\section{RESULTS}

\section{Activation of spores}

Within 1 to 5 min of activation, several malacospores opened at the side opposite the polar capsules and released the sporoplasms. Immediately, the sporoplasm was seen to move slowly by formation of pseudopodia (Fig. 1). One sporoplasm remained in a position close to the remainder of the spore, while the other slowly moved along a distance of $\sim 50 \mu \mathrm{m}$ until the slide dried out. Only the primary cell contributed to the movement. In other cases, sporoplasms left the spore but did not show further movement after contact with water, although formation of pseudopodia could be observed (Fig. 2). Surprisingly, no polar filaments were seen to have been fired by the activated spores, although the sporoplasms were released.

\section{SEM}

Spores of Tetracapsuloides bryosalmonae could be successfully prepared for SEM, although the final spore number on the slide was low due to high losses during processing. Fig. 3A shows a top view of a malacospore. Four visible valve cells almost completely cover the polar capsules. Polar filaments were fired in some spores (Fig. 3B), probably due to denaturation of integral components by the fixative. Only a small

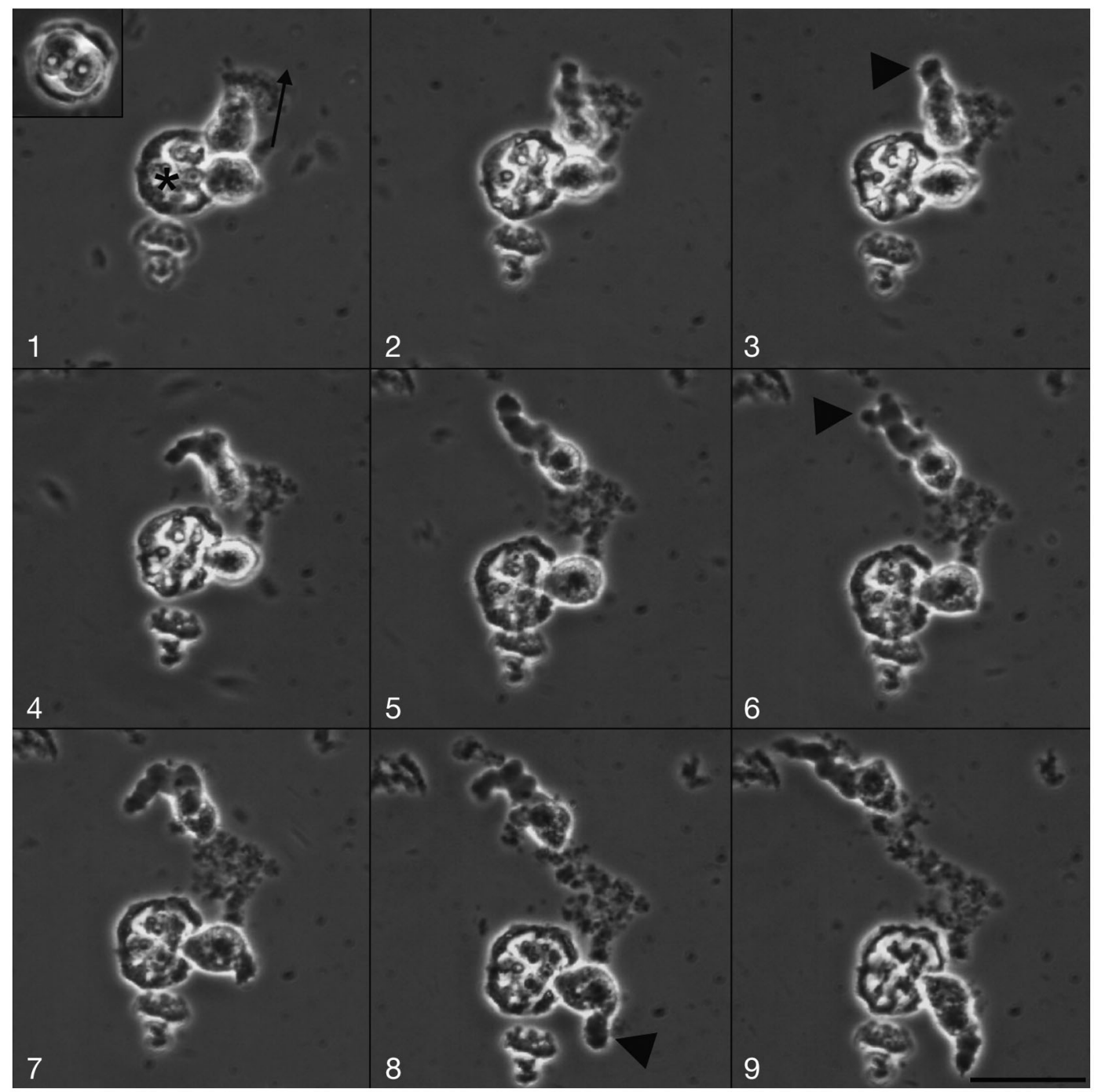

Fig. 1. Tetracapsuloides bryosalmonae. Time-sequence of a malacospore activated by the addition of trout mucus homogenate and pipetting up and down. Inset in top left corner: non-activated spore for comparison. Arrow: sporoplasms leaving the spore and one starting to move upwards. Arrowheads: formation of pseudopodia in both cells. (*) Remains of spores (valve cell and capsulogenic cells with polar capsules). Scale bar $=25 \mu \mathrm{m}$ 

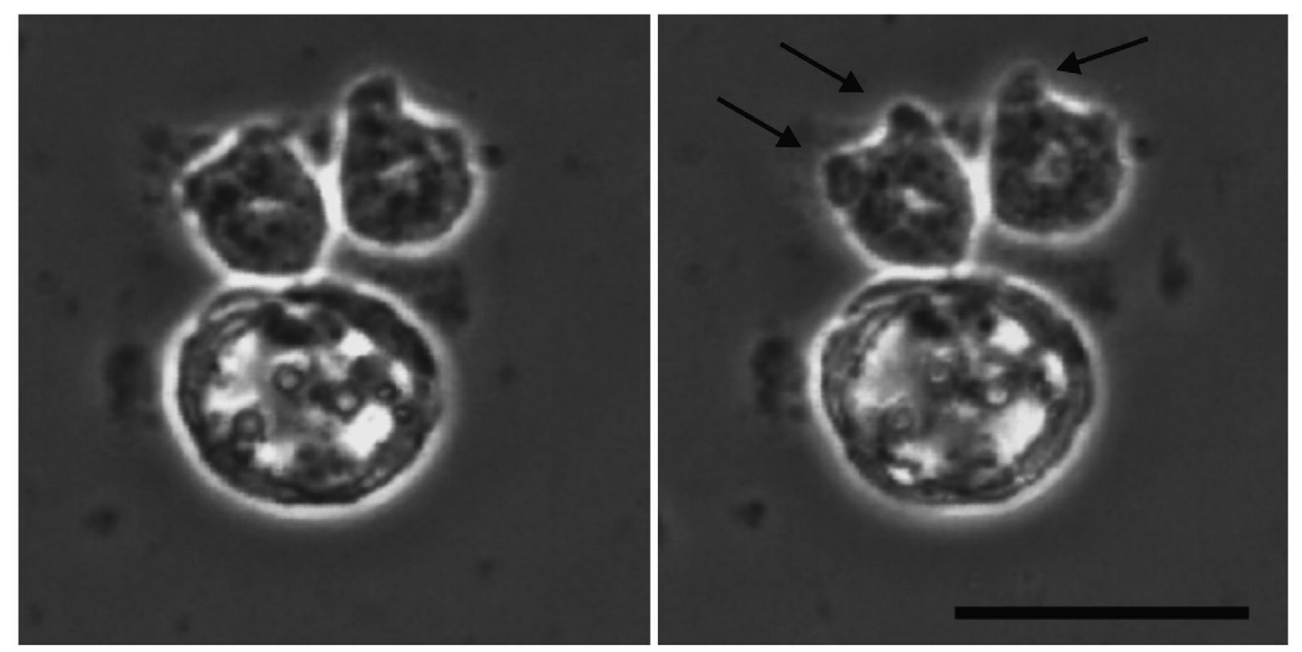

Fig. 2. Tetracapsuloides bryosalmonae. A malacospore activated by the addition of trout mucus homogenate and pipetting up and down. Arrows: sporoplasms leaving the spore and forming pseudopodia. Scale bar $=25 \mu \mathrm{m}$
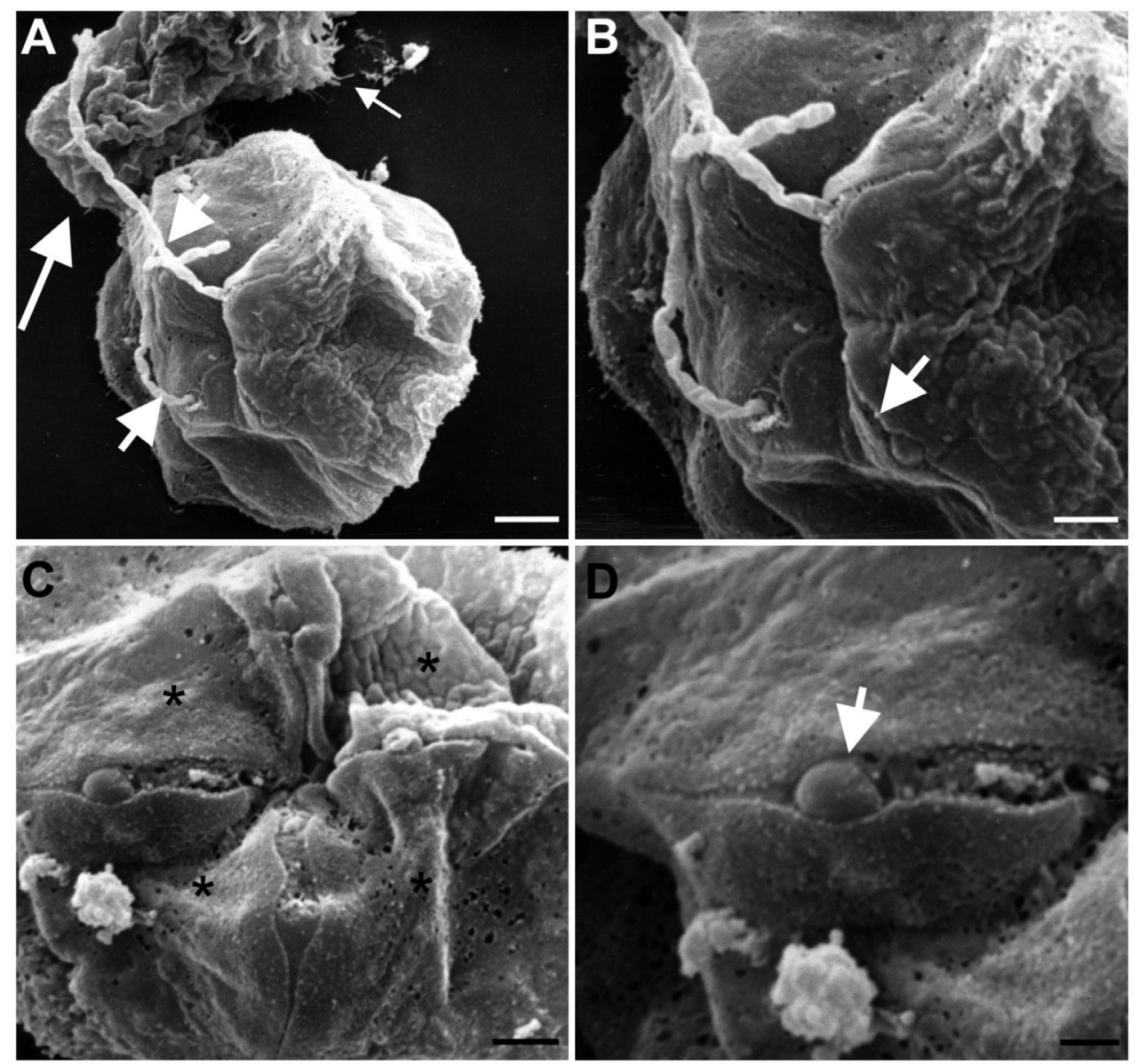

Fig. 3. Tetracapsuloides bryosalmonae. Scanning electron micrographs of malacospores obtained from dissected Fredericella sultana. (A) Top view of a spore with its 4 polar capsules covered by valve cells. Short arrows: two polar filaments being fired. Large arrow: sporoplasm leaving the spore at the bottom side. Small arrow: formation of pseudopodia. Scale bar $=2 \mu \mathrm{m}$. (B) Higher magnification of (A). Arrow: suture lines of 2 valve cells. Scale bar $=1 \mu \mathrm{m}$. (C) Apical view of polar capsule region. (*) Plugs sealing the openings of the polar capsules between the 4 valve cells. Scale bar $=1 \mu$ m. (D) Higher magnification of (C) showing plug (short arrow). Scale bar $=500 \mathrm{~nm}$ 
opening for the polar filament remained along the suture line of 2 valve cells (Fig. 3B,C), which was sealed by a plug-like insertion (Fig. 3D). One sporoplasm could be seen leaving the spore at the bottom side, showing pseudopodial processes. No spores could be found on the gills or on the body surface of $T$. bryosalmonae-exposed trout.

\section{TEM}

In the light microscopy of immunohistochemically stained paraffin sections, spores attached to the gills were seen at all time points, with the highest number of spores (1 to 4 per section of a total gill arch) being observed at 20 min post exposure (pe) (Fig. 4A). Some
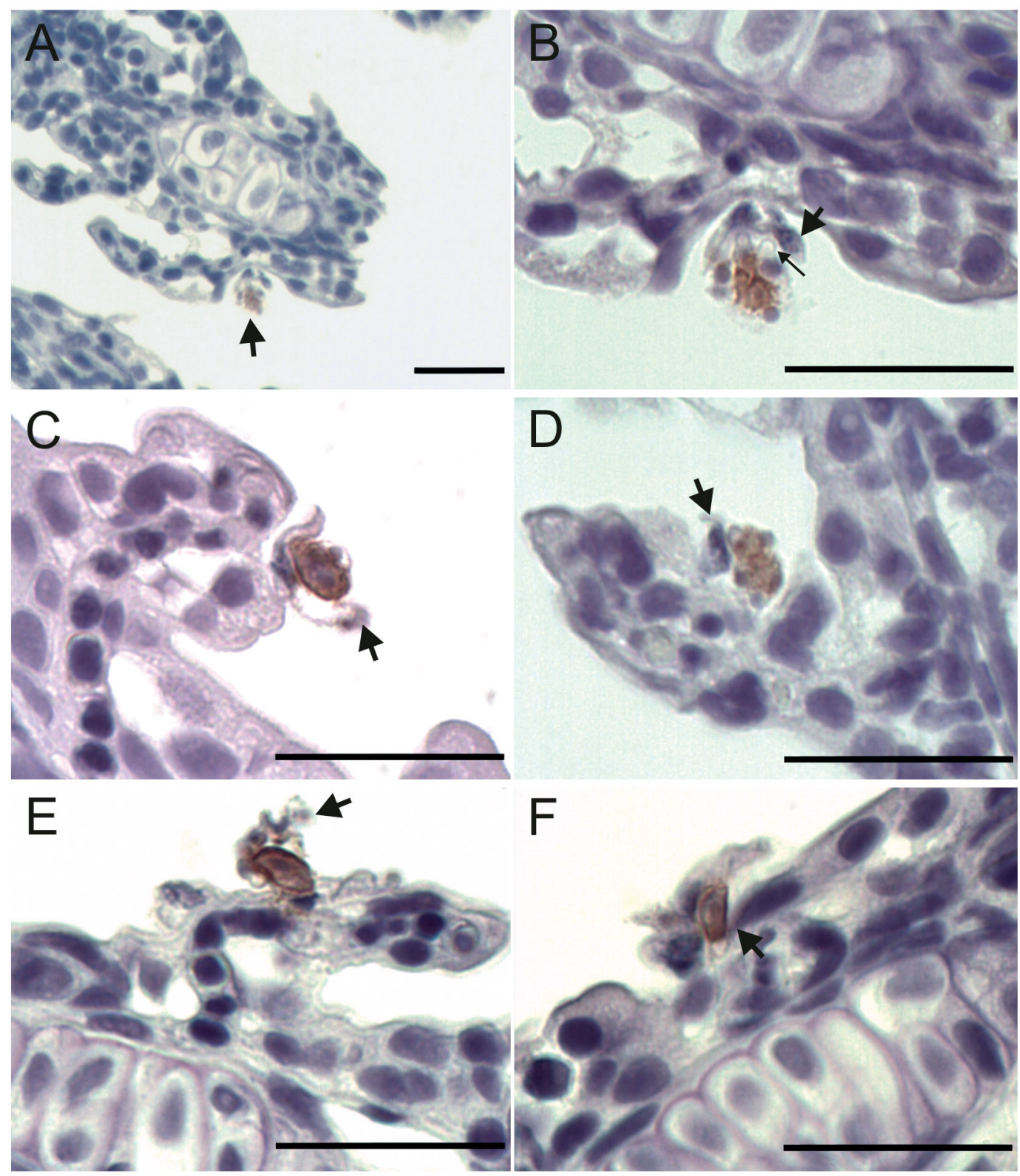

Fig. 4. Tetracapsuloides bryosalmonae. Photomicrographs of spores attached to gill sections of exposed rainbow trout. (A) Arrow: spore attached to gill at 20 min post exposure (pe). (B) Higher magnification of (A). Sporoplasm (stained brown) surrounded by unstained valve cells. Thin arrow: 2 polar capsules in plane of section. Arrow: impaired gill epithelium in the area of contact with the spore. (C) Sporoplasm attached to gill at 5 min pe. Arrow: detectable remains of valve cells. (D) Spore attached to gill at 20 min pe. Valve cells still intact. Arrow: visibly disrupted gill epithelial cell. (E) Sporoplasm during penetration at 30 min pe. Arrow: visible remains of valve cells. (F) Arrow: sporoplasm penetrating gill epithelium at 30 min pe. Immunohistochemical staining was done with haematoxylin counter stain, parasite sporoplasms being stained brown. Scale bars $=25 \mu \mathrm{m}$ 
spores had the sporoplasm still enclosed by the valve cells (Fig. 4B), but the original shape of the spore was sometimes lost and the spore shell valves opened to release the sporoplasms (Fig. 4C). In most cases, the gill epithelium was disrupted in the area of contact with the spore (Fig. 4B,D).

After 30 min pe, numerous parasite cells were observed to have penetrated the gill epithelium (Fig. 4E,F). The earliest time point when sporoplasms could be detected inside the gill tissue was 20 min pe (Fig. 5A,B). Possibly, these intraepithelial stages were heading for blood vessels, as parasite cells were seen in close contact with pillar cells after $60 \mathrm{~min}$ pe (Fig. 5C). In one section, a parasite stage was detected in deeper layers of the gill (Fig. 5D), but it could not be seen whether this penetrated stage consisted of 1 or 2 cells. No parasites were observed in deeper layers of the gill arches or inside blood vessels.

As the spore density on the gills was low, only a few parasite stages were found at $20 \mathrm{~min}$ pe in ultrathin sections in TEM. These spores were lying adjacent to the gill epithelium and were still intact, with sporo- plasms being enclosed by the valves (Fig. 6A,B). The degeneration of the gill epithelium in the area of contact with the spore was also observed in TEM (Fig. 6A). Penetrated stages in the tissue of the gills were not identified in TEM. No parasite stages were observed in the immunohistochemically stained paraffin sections of skin and fins; therefore these samples were not examined by TEM.

\section{DISCUSSION}

The results of the present study show that spores of Tetracapsuloides bryosalmonae obtained from infected bryozoans target mainly the gills as portals of entry into the fish host. These findings are in conformity with the results of Morris et al. (2000), who detected $T$. bryosalmonae stages in gill arches of rainbow trout $3 \mathrm{~d}$ after exposure to PKD-endemic waters using in situ hybridization. The authors found no other tissues to be infected at this time point. It could not be distinguished if the stained cells they detected con-
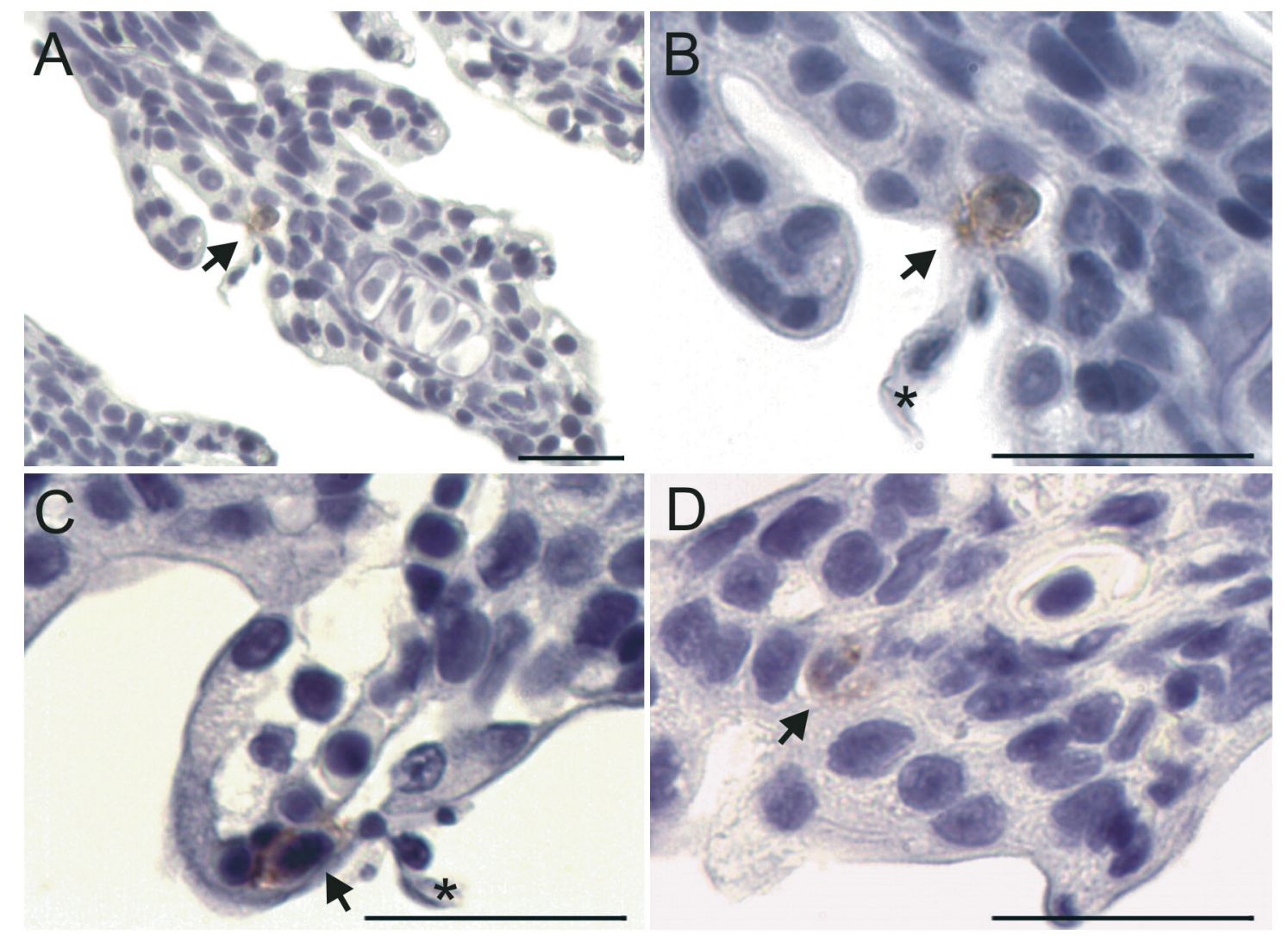

Fig. 5. Tetracapsuloides bryosalmonae. Photomicrographs of sporoplasms penetrating exposed rainbow trout gill sections. (A) Arrow: sporoplasm in gill epithelium at 20 min post exposure (pe). (B) Higher magnification of (A). Arrow: parasitic cell between epithelial cells. (C) Sporoplasm underneath gill epithelium close to a pillar cell at 60 min pe. (D) Arrow: parasitic cell in deeper layer of gill tissue at $60 \mathrm{~min}$ pe. Immunohistochemical staining with haematoxylin counter stain; parasite sporoplasms stained brown.

(*) Disrupted gill epithelium. Scale bars $=25 \mu \mathrm{m}$ 

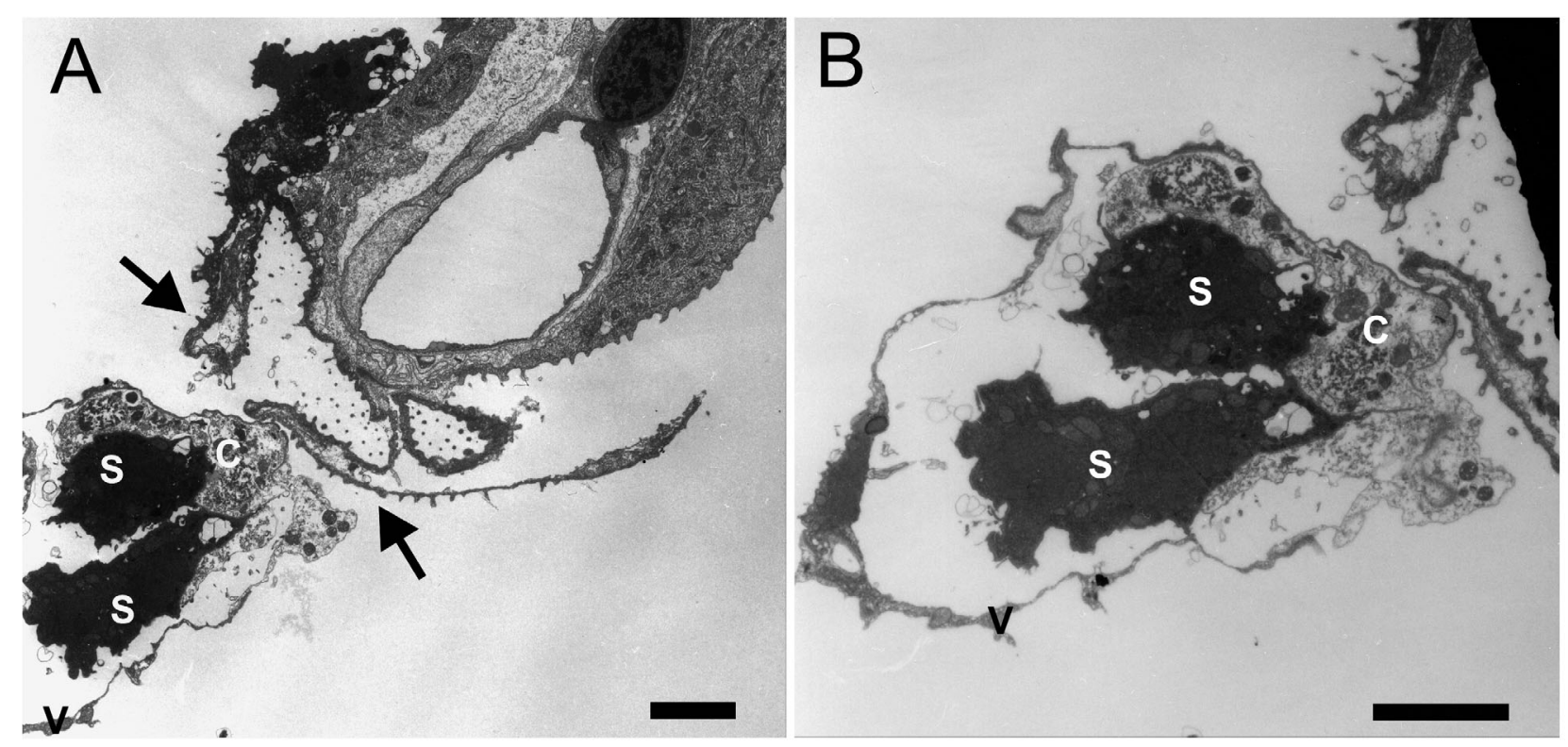

Fig. 6. Tetracapsuloides bryosalmonae. Transmission electron micrographs. (A) Spores adjacent to the gill epithelium of exposed rainbow trout. Arrows: visible impairment of gill epithelium. Scale bar $=3 \mu \mathrm{m}$. (B) Higher magnification of (A). Sporoplasms are still enclosed by valve cells. V: valve cell, C: capsulogenic cell, S: sporoplasm. Scale bar $=3 \mu \mathrm{m}$

tained secondary cells or not. Holzer et al. (2006) also demonstrated the presence of $T$. bryosalmonae stages in blood vessels of the gills in farmed brown trout (Salmo trutta) and suggested this organ to be the main route of entry for this parasite. In contrast to these findings, Longshaw et al. (2002) detected T. bryosalmonae stages mostly in or adjacent to skin mucus cells of rainbow trout after only 1 min of exposure to a homogenate of infected bryozoans using in situ hybridization. Further, at all other time points (1 to 90 min pe), the highest number of parasite stages was present in the skin. Gill stages were only found in fish that were exposed for $90 \mathrm{~min}$ and $72 \mathrm{~h}$ to the bryozoan homogenate. From the present results, penetration of $T$. bryosalmonae through the skin cannot be completely ruled out, but the absence of stages in histological sections of this organ indicates that this is at least rare.

The process of attachment and penetration to the fish host has been described thoroughly for the myxozoan Myxobolus cerebralis. This parasite was found to penetrate through the openings of mucus cells of the gills, skin, and buccal cavity of rainbow trout (El-Matbouli et al. 1999). M. cerebralis first multiplies in the epidermal cells before it migrates through the peripheral nerves and the central nervous system to the cartilage, where spores are formed (El-Matbouli et al. 1995). In contrast, Tetracapsuloides bryosalmonae is transported to the target tissue by the blood stream and no multiplication step could yet be proven prior to blood/kidney stages (Morris et al. 2000, Holzer et al. 2006). Based on the short period (detectable by histological analysis after $\sim 1 \mathrm{wk}$ ) required for the parasite to reach the target tissue (Morris et al. 2000), it can be assumed that penetrated parasite stages directly migrate towards blood vessels and infiltrate kidney tissue. The gill epithelium is the thinnest barrier between the surrounding water and the blood stream, and is therefore an ideal portal of entry for $T$. bryosalmonae. The contradictory findings of Longshaw et al. (2002) that the skin is the preferred site of entry of $T$. bryosalmonae to the fish host could not be confirmed herein. Penetration through the skin might occur occasionally, but presumably does not lead to successful infection of the fish. This was observed for penetrating stages of the aurantiactinomyxon spores of the gill-specific myxozoan Henneguya ictaluri, which were always found in the gills, but also in the skin and buccal cavity after $24 \mathrm{~h}$ pe of the fish to spores of the parasite. Only the gill stages developed further, while stages in all other organs degenerated after $96 \mathrm{~h}$ pe (Belem \& Pote 2001). A similar case can be speculated for $T$. bryosalmonae, but this does not explain why no attached spores and no penetrated sporoplasms were found in the skin in the study of Morris et al. (2000) and in the present study. Additionally, some evidence indicates that $T$. bryosalmonae preferentially enters through the gills. Spores of $T$. bryosalmonae released by the bryozoans are very small compared to other myxozoan actinospores. It was stated previously that smaller spore types usually seem to be better adapted to enter the gills than larger ones (Yokoyama \& Urawa 1997). As in $H$. ictaluri, it was found that the aurantiactinomyxon 
spores of Thelohanellus hovorkai are well adapted to penetrate the gills (Yokoyama \& Urawa 1997). In contrast, the larger raabeia spores of Myxobolus cultus were found to penetrate the skin and fins but not the gills, and the triactinomyxon spores of Myxobolus arcticus entered through the skin and fins but rarely through the gills (Yokoyama \& Urawa 1997). The smaller size of spores possibly leads to an increased oral uptake by the fish and therefore also an increased likelihood of contact with the gills than with the skin.

Furthermore, based on the histological examination in the present study, the actual penetration of the sporoplasm into the gills took quite a long time. The first sporoplasms penetrating the gill epithelium were found at $30 \mathrm{~min}$ pe. Before this time, only intact spores adjacent to the gills were detected in histological sections, with sporoplasms still being enclosed by valve cells. Mechanisms and stimuli that induce actinospore activation, firing of polar filaments and release of the sporoplasm have been investigated in previous studies (Kallert et al. 2005, Yokoyama et al. 2006, Kallert et al. 2007). Differences in reaction time after chemical or a combination of chemical and mechanical stimulation were noted between actinospores of various myxozoan species. Thelohanellus hovorkai aurantiactinomyxon spores and Myxobolus parviformis triactinomyxon spores needed a longer time to release their sporoplasms than triactinomyxon spores of Myxobolus arcticus and the triactinomyxon spores of Myxobolus cerebralis (Yokoyama et al. 2006, Kallert et al. 2007). The first 2 species are gillspecific and also show some morphological similarities. Their spores are rather small and the tips of the polar capsules do not significantly protrude above the apical region of the spore. The latter 2 species penetrate via various tissues, mostly the skin, and have large spores with protruding polar capsule tips. As discussed by Kallert et al. (2007), these morphological and behavioural characteristics are likely to be specializations to the respective portal of entry. The spores of Tetracapsuloides bryosalmonae are also small and SEM observations show polar capsules that are almost entirely covered by the valve cells. In this context, it has to be noted that no polar filaments were fired by mucus-activated spores of $T$. bryosalmonae, although sporoplasms were leaving the spore and starting to move. This was also the case for activated spores of $M$. parviformis (Kallert et al. 2007), indicating that additional or different stimuli are required to induce the release of the polar filament. The observed preference of some species for the gills could also be due to the excretion of various ions through this organ in the required concentration (that may not be present in the mucous layer of the skin) to trigger the polar capsules.
These findings show that to some extent, conclusions on the site of entry can be drawn from the size and morphology of the spore and further substantiate that the gill is the preferred portal of entry for spores of Tetracapsuloides bryosalmonae. In this respect, it should be noted that the malacospores of $T$. bryosalmonae are spherical and do not have a style and caudal projections. Nothing is known about the functional morphology of different actinospore types, but the lack of caudal projections indicates that malacospores sink faster than other actinospores. This complies with the short life span of these spores (de Kinkelin et al. 2002). It can be assumed that contact with the fish host must occur shortly after the release of spores by bryozoans.

After the attachment of a malacospore to the fish host, most of the spore 'body' is discarded and only the sporoplasm remains and penetrates the tissue. This process was also observed for other myxozoans. For example, the amoeboid movement of the sporoplasm by formation of pseudopodia was observed for Myxobolus cerebralis in histological sections and in sporoplasms released from activated spores (Markiw 1989, El-Matbouli et al. 1995, Eszterbauer et al. 2009). The observation of activated spores on a glass slide in the present study showed for the first time that sporoplasms of Tetracapsuloides bryosalmonae move in an amoeboid fashion upon attachment to the host. In contrast to $M$. cerebralis, that was found to penetrate mostly through the openings of the mucus cells (ElMatbouli et al. 1999), spores of $T$. bryosalmonae seemed to impair the gill epithelium upon attachment. The invasion of sporoplasms seemed to occur through the gill epithelium; however, it is still possible for penetration to occur through the openings of the mucus cells. As suggested by Morris \& Adams (2008), it is likely that the sporoplasm becomes the proliferating cell doublet after penetration. No indication for a release of the sporoplasm cell from the primary sporoplasm could be found in the present study.

McGurk et al. (2005) investigated spores of Tetracapsuloides bryosalmonae using confocal laser scanning microscopy and found 8 valve cells: 4 on the upper half of the spore covering the capsulogenic cells and 4 on the lower half. In the SEM observations of $T$. bryosalmonae in the present study, only the 4 upper cells were seen, as only the apical side of the spores was visible. The reason for this effect is unclear. There appears to be a preference for this 'upside-up' orientation of the spores during the cytospin preparation of the SEM samples. It was also observed that the suture line of 2 valve cells was located over the polar capsules and left an opening for the polar filament. The umbrella-like plug, which is characteristic for malacosporean spores described previously in electron 
microscopical studies (Canning et al. 2002, Morris \& Adams 2007), was also visible from the outside of the spore in SEM. It was not obvious how this plug is removed when the polar filament is fired. No conclusion could be drawn from the comparison of polar capsule openings with and without released polar filaments. The lack of parasite stages on the gills and on whole fish prepared for SEM may be explained by a loss of these stages during processing of the samples. Improvement and optimization of the processing procedure are required for investigating the attachment and penetration process of $T$. bryosalmonae using SEM.

In conclusion, the present study provided further evidence for the hypothesis that the gills are the preferred portal of entry of Tetracapsuloides bryosalmonae to the fish host. Penetrating stages of this parasite on the gills were visualized using light microscopy for the first time. The low spore numbers on the gills hampered detailed TEM studies of penetrating stages inside the gill tissues. Further studies with higher spore numbers and longer exposure times are required to characterize the morphology of the early stages of $T$. bryosalmonae in the fish host and to allow conclusions about the fate of sporoplasms penetrating the skin.

Acknowledgements. The authors thank D. Kallert for help with the spore activation experiments, helpful discussions and corrections of the manuscript. This study was funded by German Science Foundation (Deutsche Forschungsgemeinschaft, DFG) Grant No. EL 174/5-1.

\section{LITERATURE CITED}

Anderson CL, Canning EU, Okamura B (1999) Molecular data implicate bryozoans as hosts for PKX (phylum Myxozoa) and identify a clade of bryozoan parasites within the Myxozoa. Parasitology 119:555-561

Belem AM, Pote LM (2001) Portals of entry and systemic localization of proliferative gill disease organisms in channel catfish Ictalurus punctatus. Dis Aquat Org 48:37-42

Canning EU, Tops S, Curry A, Wood TS, Okamura B (2002) Ecology, development and pathogenicity of Buddenbrockia plumatellae Schröder, 1910 (Myxozoa, Malacosporea) (syn. Tetracapsula bryozoides) and establishment of Tetracapsuloides n. gen. for Tetracapsula bryosalmonae. J Eukaryot Microbiol 49:280-295

> Clifton-Hadley RS, Bucke D, Richards RH (1987) A study of the sequential clinical and pathological changes during proliferative kidney disease in rainbow trout, Salmo gairdneri Richardson. J Fish Dis 10:335-352

de Kinkelin P, Gay M, Forman S (2002) The persistence of infectivity of Tetracapsula bryosalmonae-infected water for rainbow trout, Oncorhynchus mykiss (Walbaum). J Fish Dis 25:477-482

El-Matbouli M, Hoffmann RW, Mandok C (1995) Light and electron microscopic observations on the route of the triactinomyxon-sporoplasm of Myxobolus cerebralis from epidermis into rainbow trout cartilage. J Fish Biol 46: 919-935
El-Matbouli M, Hoffmann RW, Schoel H, McDowell TS, Hedrick RP (1999) Whirling disease: host specificity and interaction between the actinosporean stage of Myxobolus cerebralis and rainbow trout Oncorhynchus mykiss. Dis Aquat Org 35:1-12

Eszterbauer E, Kallert DM, Grabner D, El-Matbouli M (2009) Differentially expressed parasite genes involved in host recognition and invasion of the triactinomyxon stage of Myxobolus cerebralis (Myxozoa). Parasitology 136: 367-377

Ferguson HW, Needham EA (1978) Proliferative kidney disease in rainbow trout Salmo gairdneri Richardson. J Fish Dis 1:91-108

Grabner DS, El-Matbouli M (2008) Transmission of Tetracapsuloides bryosalmonae (Myxozoa: Malacosporea) to Fredericella sultana (Bryozoa: Phylactolaemata) by various fish species. Dis Aquat Org 79:133-139

Hedrick RP, MacConnell E, de Kinkelin P (1993) Proliferative kidney disease of salmonid fish. Annu Rev Fish Dis 3:277-290

Holzer AS, Sommerville C, Wootten R (2006) Molecular studies on the seasonal occurrence and development of five myxozoans in farmed Salmo trutta L. Parasitology 132: 193-205

> Kallert DM, El-Matbouli M, Haas W (2005) Polar filament discharge of Myxobolus cerebralis actinospores is triggered by combined non-specific mechanical and chemical cues. Parasitology 131:609-616

Kallert DM, Ponader S, Eszterbauer E, El-Matbouli M, Haas W (2007) Myxozoan transmission via actinospores: new insights into mechanisms and adaptations for host invasion. Parasitology 134:1741-1750

Kent ML, Hedrick RP (1986) Development of the PKX myxosporean in rainbow trout Salmo gairdneri. Dis Aquat Org 1:169-182

> Longshaw M, le Deuff RM, Harris AF, Feist SW (2002) Development of proliferative kidney disease in rainbow tout, Oncorhynchus mykiss (Walbaum), following short-term exposure to Tetracapsula bryosalmonae infected bryozoans. J Fish Dis 25:443-449

> Markiw ME (1989) Portals of entry for salmonid whirling disease in rainbow trout. Dis Aquat Org 6:7-10

> McGurk C, Morris DJ, Bron JE, Adams A (2005) The morphology of Tetracapsuloides bryosalmonae (Myxozoa: Malacosporea) spores released from Fredericella sultana (Bryozoa: Phylactolaemata). J Fish Dis 28:307-312

McGurk C, Morris DJ, Auchinachie NA, Adams A (2006) Development of Tetracapsuloides bryosalmonae (Myxozoa: Malacosporea) in bryozoan hosts (as examined by light microscopy) and quantitation of infective dose to rainbow trout (Oncorhynchus mykiss). Vet Parasitol 135: 249-257

> Morris DJ, Adams A (2007) Sacculogenesis and sporogony of Tetracapsuloides bryosalmonae (Myxozoa: Malacosporea) within the bryozoan host Fredericella sultana (Bryozoa: Phylactolaemata). Parasitol Res 100:983-992

> Morris DJ, Adams A (2008) Sporogony of Tetracapsuloides bryosalmonae in the brown trout Salmo trutta and the role of the tertiary cell during the vertebrate phase of myxozoan life cycles. Parasitology 135:1075-1092

> Morris DJ, Adams A, Richards RH (2000) In situ hybridisation identifies the gill as a portal of entry for PKX (Phylum Myxozoa), the causative agent of proliferative kidney disease in salmonids. Parasitol Res 86:950-956

Morris DJ, Morris DC, Adams A (2002) Development and release of a malacosporean (Myxozoa) from Plumatella repens (Bryozoa: Phylactolaemata). Folia Parasitol 
(Prague) 49:25-34

Okamura B, Wood TS (2002) Bryozoans as hosts for Tetracapsula bryosalmonae, the PKX organism. J Fish Dis 25: $469-475$

> Okamura B, Anderson CL, Longshaw M, Feist SW, Canning EU (2001) Patterns of occurrence and 18S rDNA sequence variation of PKX (Tetracapsula bryosalmonae), the causative agent of salmonid proliferative kidney disease. J Parasitol 87:379-385

Sterud E, Forseth T, Ugedal O, Poppe TT and others (2007) Severe mortality in wild Atlantic salmon Salmo salar due to proliferative kidney disease (PKD) caused by Tetracap-

Editorial responsibility: Dieter Steinhagen,

Hannover, Germany suloides bryosalmonae (Myxozoa). Dis Aquat Org 77: 191-198

Wahli T, Knuessel R, Bernet D, Segner H and others (2002) Proliferative kidney disease in Switzerland: current state of knowledge. J Fish Dis 25:491-500

Yokoyama H, Urawa S (1997) Fluorescent labelling of actinospores for determining the portals of entry into fish. Dis Aquat Org 30:165-169

Yokoyama H, Kim JH, Urawa S (2006) Differences in host selection of actinospores of two myxosporeans, Myxobolus arcticus and Thelohanellus hovorkai. J Parasitol 92: $725-729$

Submitted: February 16, 2010; Accepted: May 4, 2010

Proofs received from author(s): June 9, 2010 